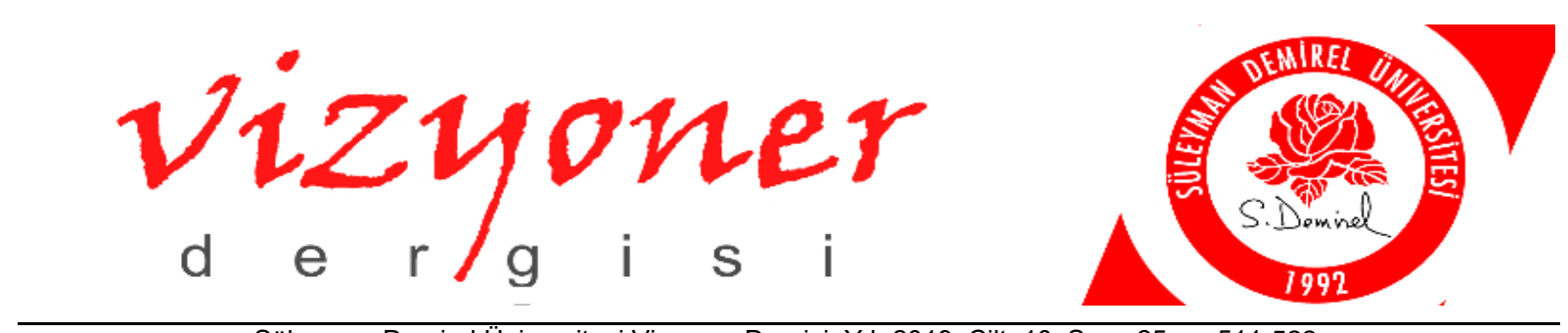

Süleyman Demirel Üniversitesi Vizyoner Dergisi, Yıl: 2019, Cilt: 10, Sayı: 25, ss.511-522.

Suleyman Demirel University Visionary Journal, Year: 2019, Volume: 10, Number: 25, pp.511-522.

ARAŞTIRMA MAKALESİ / RESEARCH ARTICLE

\title{
HASTANE MOBİL UYGULAMALARINDA KULLANICI YORUMLARININ INCELENMESI*
}

\section{INVESTIGATION OF USER COMMENTS ON HOSPITAL MOBILE APPLICATIONS}

\author{
Doç. Dr. Mahmut AKBOLAT ${ }^{1}$ \\ Yonca YILDIRIM² \\ Arş. Gör. Mustafa AMARAT ${ }^{3}$
}

ÖZ

Bu çalışmada, Google Play Store ve Apple Store uygulama mağazalarında yer alan hastane mobil sağlık uygulamalarının içeriklerinin incelenip, kullanıcılar tarafından yapılan yorumlarının değerlendirilerek mobil sağlı uygulamaların hangi amaçlarla kullanıldığı ve kullanım sırasında yaşanan sorunların ortaya konulması amaçlanmaktadır. Araştırmada Google Play Store ve Apple Store uygulama mağazalarında 5.000 ve üzeri indirme sayısına sahip 2 özel, 3 kamu hastanesine ait mobil sağlık uygulamalarına 2016-2018 yılları arasında yapılan yorumlar veri olarak kullanılmıştır. Verilerin analizi, Nvivo 12 nitel veri analizi programı aracılığıyla içerik analizi yöntemi kullanılarak yapılmıştır. Ortaya çıkan temalar; randevu, sağlık kayıtları, erişim, fayda sağlama, kullanılabilirlik, güvenliktir. Sonuç olarak; hastane mobil uygulamalarının randevu alımında, laboratuvar ve muayene sonuçlarına erişimde, kişisel sağlık durumlarını kontrol etmede kullanıldığı görülmüştür. Randevu alımında doktor seçilmemesi, ilgili bölümün seçilememesi, randevu iptalinin yapılamaması gibi sorunlarla karşılaşıldığı, laboratuvar ve muayene sonuçlarında pdf dosya olarak kaydetme konusunda problemler yaşandığı, raporların bazen görüntülenemediği sonuçlarına ulaşılmıştır.

Anahtar Kelimeler: Mobil Teknolojiler, Hastane, Hastane Mobil Uygulamaları, Mobil Sağlık Uygulamaları.

JEL Sinıflandırma Kodları: I10, O30, O32, O33, M1.

\begin{abstract}
In the study, the contents of the mobile healthcare applications in the Google Play Store and Apple Store application stores are examined and the interpretations made by the users are evaluated and the purposes of the mobile health applications are evaluated. The data used in the study are the comments made between 2016-2018 on the mobile health applications of 2 private and 3 public hospitals in the Google Play Store and Apple Store application stores with a download number of 5,000 and more. The data are analysed using the content analysis method through the Nvivo 12 qualitative data analysis program. The main themes of the study are appointment, health records, access, benefit, availability, security. As a result; it is seen that hospital mobile applications are

* Bu çalışma 2.Uluslararası ve 12. Ulusal Sağlık ve Hastane İdaresi Kongresinde sunulmuştur.

Sakarya Üniversitesi, İşletme Fakültesi, Sağlık Yönetimi Bölümü, makbolat@sakarya.edu.tr, https://orcid.org/0000-0002-2899-6722

2 Sakarya Üniversitesi, İşletme Enstitüsü, Sağlık Yönetimi Anabilim Dalı, Yüksek Lisans Öğrencisi, yoncaa.yildirim@gmail.com, https://orcid.org/0000-0001-8537-6602

3 Sakarya Üniversitesi, İşletme Fakültesi, Sağl1k Yönetimi Bölümü, mustafaamarat@sakarya.edu.tr, https://orcid.org/0000-0001-8954-6314
\end{abstract}


used in appointment, laboratory and examination results, and to control personal health conditions. In the appointment, there are problems such as not choosing a doctor, not being able to select the relevant department, the cancellation of the appointment, the results of the laboratory and the results of the examination as a pdf file are recorded and the reports could not be displayed.

Keywords: Mobile Technologies, Hospital, Hospital Mobile Applications, Mobile Health Applications.

JEL Classification Codes: I10, O30, O32, O33, M1.

\section{GIiRIŞ}

Mobil uygulamaların kısa geçmişinde öncelikle insan ihtiyaçları için geliştirildiği daha sonrasında insan hayatını kolaylaştırmaya ve pratikleştirmeye yönelen bir tutum içerisinde olduğu görülmektedir (Uğur ve Turan, 2015: 64). Modern teknoloji, sürekli olarak insan hayatının farklı alanlarındaki etkileşim ve iletişim kanallarını değiştirmektedir. Bu değişimi sağlayan en önemli unsurlardan birisi de mobil cihaz kullanımıdır (Kırlar Can vd., 2017: 60). Mobil iletişim teknolojileri olarak adlandırılan akıllı telefonlar, tabletler gibi teknolojik ürünler sadece iletişim ve sosyalleşme aracı olarak değil, çok çeşitli fonksiyonların icra edilebileceği cihazlar olarak tasarlanıp geliştirilmektedir (Singh vd., 2014: 606). Bu teknolojiler birçok alanda kullanılabildiği gibi bireysel sağlık ve sağlık hizmetlerinde de kullanılabilmektedir. Akıllı mobil cihazlar, elektronik sağlık (e-sağlık) uygulamaları açısından zengin içerik ve kaynaklara sahiptir (Liu vd., 2011: 2022). E-sağlık, başta internet olmak üzere bilişim ve iletişim teknolojilerinin sağlık hizmetlerinde kullanılması ile hastalıkların önlenmesi ve sağlık hizmetlerinin geliştirilmesi olarak tanımlanmaktadır (Eng, 2004: 238). E-sağlık; elektronik sağlık kayıtları (EHR), sağlık bilgi sistemleri (HIS), tele tıp ve mobil sağlık (mHealth) gibi bileşenleri içermektedir (Adibi, 2015: 1). Bu bileşenler; elektronik sağlık kayıtları, bireye özgü sağlık ve hastalık hikâyesinin, tanı, tedavi ve bakım raporlarının kayıt edildiği bilgisayar destekli kayıtlardan oluşmaktadır (Safran ve Goldberg, 2000: 77). Sağlık bilgi sistemleri, sağlık alanındaki gelişmeler ile birlikte ortaya çıkan bilgi ve verilerin oluşturulması, düzenlenmesi, paylaşılması ve hastaların tanı ve tedavilerinin belirlenmesi ve geliştirilmesi gibi işlemlerinin bütününe verilen isimdir (Göktaş vd., 2014: 127). Sağlık bilgi sistemlerinin kullanılması ile etkili ve yüksek kalitede hasta bakımına katkıda sağlanması amaçlanmaktadır (Haux, 2006: 270). Tele tıp ise bireylerin ve toplumların sağlık düzeylerinin iyileştirilmesi, hastalıkların ve kazaların önlenmesi; sağlık personellerinin sürekli eğitimi ile tüm sağlık profesyonelleri tarafından bilgi ve iletişim teknolojileri kullanılarak, uzaktan ve geçerli bilgi iletişim yöntemleri ile sağlık hizmetleri verilmesi olarak tanımlanmaktadır (WHO, 2010: 9). Mobil sağlık ise TÜSİAD' in 2016 yılında yayınladığı mobil sağlı̆̆a yönelik raporda, toplumu bilinçlendirme, hastalıklar hakkında uyarılarda bulunma ve yönlendirme amaçlı SMS mesajlarından, görüntülü telekonsültasyon ve teleziyaret uygulamalarına; cep telefonundan veya internet sitesinden randevu almaktan, taşınabilir veya giyilebilir cihazlardan tıbbi verilerin gönderilmesine; bireyin akıllı telefon uygulamaları ile kendine renk körlüğü testi uygulamasından, uzaktan kronik hastalık yönetimine kadar çok geniş bir yelpazede uygulama alanı bulmak olarak ifade edilmektedir (Tezcan, 2016: 14). Sağlık hizmetlerinde süreçler üzerinde değişiklikler yaratan mobil sağlık, hizmet süreci üzerinde de önemli iyileştirmeler yapabilme potansiyeline sahiptir (Free vd., 2013:2).

Sağlık hizmetlerinde mobil uygulamaların gelişimi de mobil cihazların fonksiyonelliğini arttırarak mobil bilgi işlem ve iletişim teknolojilerinin sağlık hizmetlerinin içine daha çok dâhil edilmeye başlamasını sağlamıştır (Owensbya ve Kavookjianb, 2017: 569; Mechael, 2009: 103). Yazılım uygulama endüstrisine göre, 2015 y1lında dünya genelinde yaklaşık 500 milyon akıllı telefon kullanıcısı bir mobil sağlı uygulaması kullanıyorken günümüzde sağlık profesyonelleri, hastalar ve hasta yakınları da dâhil olmak üzere 3,4 milyondan fazla akıllı telefon ve tablet kullanıcısının neredeyse yarısı mobil sağlık uygulamalarını kullanmaktadır (Kuersten, 2010: 1).

Teknoloji günlük hayatın vazgeçilmez bir parçası haline gelmesi ile birlikte sağlık hizmetlerinde kullanılmaya başlanmıştır (Kumar vd., 2013: 228) ve bu durum mobil sağlık uygulamalarının ortaya çıkmasına neden olmuştur. Mobil sağlık uygulamaları hekimlerin hastasının bilgilerine anlık olarak erişebilmesi, zaman ve mekân sınırı olmadan hastası ile ilgilenebilmesi, anlık olarak veri girişinin ve raporlamanın yapılabilmesinde kullanılmaktadır (Ağaç, 2014: 65). Uygulama kullanıcıları hekimler veya hastalar daha iyi bir sağlık takibinde bulunabilmektedirler. Örneğin, kalp atış/tansiyon kontrolü yapmak, kalori hesaplamak, ilaç kullanım zamanlarını kontrol etmek, gebelik sürecini takip etmek gibi birçok durum için mobil uygulamalar kullanılmaktadır (Güler ve Eby, 2015: 45). Bunların yanı sıra mobil sağlık uygulamaları, bireysel ve toplumsal düzeyde bireylerin sağlık durumlarının sürekli izlenmesini destekleyerek sağlık sorunlarını önlemek veya azaltmak için sağlıklı yaşam davranışlarını teşvik edebilmektedir (Kumar vd., 2013: 229). Hastane mobil uygulamaları ise, hastanelerin hastalarını daha kolay 
randevu almalarını, teşhis ve tahlil sonuçlarını görmelerini sağlayan mobil uygulamalardır. Bu uygulamalar günümüzde App Store ve Google Play Store'da ve hastanelerin web sayfalarında erişime açık şekilde bulunmaktadır. Her birey bu uygulamaları akıllı telefonlarına indirebilmekte ve hastanelerin kendilerine sundukları içeriklere erişebilmektedir.

Mobil sağlık uygulamaları, gelişmiş ülkelerde akıllı telefona sahip bireyler arasında kronik hastalıkları yönetmek ve sağlığı geliştirme uygulamaları için kullanılırken, gelişmekte olan ülkelerde yazılı ve sesli mesaj gönderme özelliklerine sahip mobil telefonlarla daha çok bulaşıcı hastalıkların, anne-çocuk ölümlerinin azaltılması amacıyla kullanılmaktadır (Öney Doğanyiğit, 2014: 54). Türkiye'de de mobil sağlık uygulama kullanımı zamanla artmış ve (Öney Doğanyiğit, 2013: 1) sağlık hizmetleri uygulamalarında mobil sağlık uygulamaları giderek geniş bir yer kaplamaktadır. Mobil uygulamalar sigara bırakma, kilo yönetimi, diyabet, hipertansiyon, kanser gibi uzun dönemli kronik hastalıkların yönetiminde, bazı davranışların değişikliğinde, cerrahi işlemler sonrası hastaların gözlenmesinde kullanılmaktadır (Semple vd., 2015: 2).

Sağlık hizmetleri önemli ve riskli bir alan olduğu için mobil uygulamalar geliştirilirken dikkatli ve özenli olunması gerekmektedir (Güler ve Eby, 2015: 46). Hasta-sağlık profesyonel ilişkilerini etkili bir şekilde yönetecek, sağlık hizmetlerine erişimi ve bu hizmetleri karşılayabilirliği kolaylaştıracak, böylece sağlık hizmeti sunumunda inovatif bir dönüşüm sağlayacak, bölgesel ve ulusal düzeyde hasta profillerinin belirlenmesini mümkün kılacak mobil sağlık uygulamalarının geliştirilmesi önemli bir durumdur (Singh, Wilkinson ve Braganza, 2014: 606-608). Geliştiren mobil uygulamaların kaliteli, faydalı, verimli, doğru, gizlilik ve mahremiyet gibi konularda güvenli olmaları gerekmektedir (Mandl vd.,2015: 13).

Amacına uygun olarak geliştirilen mobil sağlık uygulamalarının sağlık kuruluşlarına, hekimlere ve hastalara çeşitli faydalar sağlayacağı öngörülmektedir. Bu faydalar;

- Verilen hizmete bir geri ödeme bölümünün eklenmesi ile maliyetler azaltılabilir

- Mobil sağlık uygulamaları ile birlikte sağlık sunucusu ve hasta, istediği bilgiye anında erişim imkânı elde edebilmekte ve hekim yazılıma bağlı bulunan cihaz üzerinden hastasına gerekli bilgileri yüksek transfer hızında ve düşük maliyetle iletebilmektedir (Patil, 2011: 320).

- Kardiyovasküler, diyabet, hipertansiyon vb. kronik hastalıklara sahip hastaların kendi sağlık durumlarını kişisel sağlık kayıtları ile yönetebilecek düzeye gelmeleri sağlık kurumu ve profesyoneli üzerindeki yükü hafifletmeye imkân sağlayabilecektir (Arslan ve Demir, 2017: 33).

- Mobil sağlık uygulamaları, bireylerin kendi sağlıklarını takip etmelerine, kısa ve uzun vadede yaşam tarzlarını geliştirmek için kendilerini izlemelerine, kendilerine ait sağlık bilgilerine istedikleri zaman ve yerden erişebilmeleri için firsatlar sunmaktadır (Güler ve Eby, 2015: 46; Holzinger vd., 2010: 77).

Mobil sağlık uygulamalarının faydalarının yanı sıra bazı dezavantajları da mevcuttur. Bu dezavantajlar;

- Hastanın sağlık bilgilerinin mobil uygulamalarda her an erişime açık hale getirilmesi güvenlik açısından risk taşımaktadır. Bu durum sağlık hizmetlerini olumsuz etkileyebilir. Sistemin sağlıklı bir şekilde yürümesi için hasta bilgilerinin mahremiyetine önem verilmeli ve gerekli önlemler alınmalıdır (Demir ve Arslan, 2017: 81).

- Kronik hastalıkları ve fiziksel problemleri olan bireylerin diyet ve egzersiz uygulamalarını profesyonel destek almadan kullanmaları farklı sağlık sorunlarına yol açabilir (Kopmaz ve Arslanoğlu, 2018: 254).

Türkiye'de Sağlıkta Dönüşüm Programı ile yıl içerisinde hasta muayene sayılarında artış görülmekte fakat sağlık personeli sayısının artışında benzer oranları görülmemektedir. Bu durum sağlık hizmetlerinin sunumunda bir takım aksaklıkların yaşanmasına sebebiyet vermektedir. Bu aksaklıkları daha aza indirme yollarından birisi de mobil teknolojilerinden faydalanmaktır (Arslan ve Demir, 2017: 18). Fakat mobil uygulamalar kullanıcılar için kafa karışıklığına ve birçok farklı problemin yaşanmasına sebebiyet vermektedir. Bu sebeple hastanelere ait mobil uygulamalarının incelenip, kullanıcılar tarafından yapılan yorumlarının değerlendirilerek mobil sağlık uygulamaların hangi amaçlarla kullanıldığı ve kullanım sırasında yaşanan sorunların ortaya konulması bu çalışmanın amacını oluşturmaktadır. Bu sayede hastanelerin oluşturdukları mobil uygulamaların içeriklerinin neler olduğu tespit edilecek ve uygulamalar hakkında kullanıcıların yorumları belirlenecektir. Ayrıca, yerli ve yabancı literatürde benzer bir çalışma ile karşılaşılmadığı için alan literatürüne katkı sağlayacaktır. 


\section{YÖNTEM}

Hastaneler geliştirdikleri mobil uygulamalar sayesinde bireylerin sağlık ihtiyaçlarının giderilmesine katkı sağlayabilecektir. Mobil uygulamalar geliştirilirken kullanıcılar tarafından yapılan yorumların incelenip, mobil uygulamalardan beklentileri ortaya konulduğunda hastaneler mobil uygulamalar geliştirirken nelere dikkat etmeleri gerektiğini göreceklerdir. Bu durum hastanelerin daha başarılı mobil uygulamalar geliștirmesine katkı sağlayacaktır. Böylece mobil uygulamaların sağlayacağı fayda düzeyinde artış olacağı düşünülmektedir. Bu araştırmada, Google Play Store ve Apple Store uygulama mağazalarında yer alan ve Türkiye'de hizmet vermekte olan hastanelerin mobil uygulamalarının incelenip, kullanıcılar tarafından yapılan yorumlarının değerlendirilerek mobil sağlık uygulamaların hangi amaçlarla kullanıldığı ve kullanım sırasında yaşanan sorunların ortaya konulması amaçlanmaktadır. Çalışma yaşanan sorunların ortaya konulması ve bu sorunlara karşı önlem alınmasına sağlayacağı katkıdan dolayı önem arz etmektedir.

Araştırmada veri toplama aracı olarak Google Play Store ve Apple Store uygulama mağazalarında indirme sayıları dikkate alınarak 5.000 ve üzeri indirme sayısına sahip hastane mobil sağlık uygulamaları tercih edilmiştir. Araştırma kapsamında toplam 642 yorum incelenmiştir. Bu hastane uygulamalarının ikisi özel, üçü ise kamu hastanesine aittir. Hastanelerin asıl isimleri çalışma kapsamında verilmemiştir. Bunun yerine a kamu hastanesi, b özel hastanesi olarak kodlanmıştır. Araştırmaya dahil olan hastanelerin mobil sağlık uygulamalarına ilişsin bilgiler aşağıda yer almaktadır.

Elde edilen veriler ilk olarak Word dosyasına daha sonra Nvivo 12 nitel veri analiz programına aktarılmıştır. Verilerin çözümlenmesinde içerik analizinden yararlanılmıştır. İçerik analizinde, temelde yapılan işlem, birbirine benzeyen verileri belirli kavramlar ve temalar çerçevesinde bir araya getirilmiştir. İçerik analizinde temel amaç, toplanan verileri açıklayabilecek kavramlara ve ilişsilere ulaşmaktır. Bu yolla veriler tanımlanmaya ve verilerin içinde saklı olabilecek gerçekler ortaya çıkarılmaya çalışılır (Yıldırım, Şimşek,2011: 35). Nvivo 12 nitel veri analizi programı aracılığıyla içerik analizi yöntemi kullanılarak veriler analiz edilmiştir.

Araştırma kapsamında incelenen veriler öncelikle kodlanmış daha sonra temalara ayrılmıştır. Kullanılan temaların açıklaması, kodlar ve temalara ait örnekler aşağıda yer almaktadır (Tablo 1).

Randevu Teması: Mobil uygulamalar üzerinden kullanıcıların randevu alması, randevu iptalinin yapılabilmesi gibi randevuyla ilgili olan tüm yorumlar randevu teması altında yer verilmiştir. Randevu teması "Memnuniyet" ve "Memnuniyetsiz" olmak üzere iki kategori altında incelenmiştir.

Sağlık kayıtları teması: Kullanıcıların sağlık kayıtlarıyla ilgili yaptığı tüm yorumlara, sağlık kayıtları teması altında yer verilmiştir. Sağlık kayıtları teması "laboratuvar ve muayene kayıtları" ve "rapor" olmak üzere iki kategoride incelenmiştir.

Erişim teması: Kullanıcıların mobil uygulamaları istedikleri her an giriş yapabilmeleri, giriş esnasında problem yaşayıp yaşamadıkları ve üye olmaları sırasında sorun yaşayıp yaşamadıklarına dair yapılan yorumlara bu tema altında yer verilmiştir.

Fayda sağlama teması: Mobil uygulamaları kullananların uygulamaları faydalı bulduklarını ifade eden yorumlara bu tema altında yer verilmiştir.

Kullanılabilirlik teması: Mobil uygulamaların ara yüzlerinin kullanışlı olup olmaması, kullanımlarının kolay veya zor olması gibi konulara yapılan yorumlar bu tema altında yer verilmiştir.

Güvenlik teması: Mobil uygulamaların kullanımının güvenli olup olmadığına dair yapılan yorumlar bu tema altında yer verilmiştir. 
Tablo 1. Tema ve Örnek Kodlar

\begin{tabular}{|c|c|}
\hline Tema ve Kategori İsimleri & Örnek Kodlar \\
\hline $\begin{array}{c}\text { Randevu } \\
\text { Memnuniyetsizlik }\end{array}$ & $\begin{array}{l}\text {...randevu almak istediğimde servis bölümünde sadece } 4 \text { dalı } \\
\text { veriyor. Bu nedenle istediğim bölüme randevu alamıyorum... } \\
\text {...randevu alırken seçtiğimiz bölüm doktorlarının adını } \\
\text { göremiyoruz... } \\
\text {...randevu sadece öğlene kadar gösteriliyor, öğleden sonrasını } \\
\text { göstermiyor. Öğleden sonrasını da gösterse daha iyi olur... } \\
\text {...randevu alma modülü arızalı... } \\
\text {...randevu iptal etmek istiyorum ama program çöküyor... } \\
\text {...kolay bir şekilde randevu aldım... } \\
\text {...randevu almak için mükemmel bir yöntem... }\end{array}$ \\
\hline $\begin{array}{l}\quad \underline{\text { Sağlık Kavıtları }} \\
\text { Laboratuvar ve Muayene Kayıtları }\end{array}$ & $\begin{array}{l}\text {...laboratuvar ve muayene sonuçlarını görebilmek güzel... } \\
\text {...tahliller çıkınca direkt görebiliyorum. Tahlil sonuçlarını } \\
\text { almak için saat } 14.30 \text { 'u bekleme derdin yok. Harika... } \\
\text {...geçmişe yönelik tüm detaylara yer vermesi harika olmuş... } \\
\text {...laboratuvar sonuçlarını ise pdf olarak kaydedebilirsek daha } \\
\text { iyi olur... } \\
\text {..raporları görüntülemede çoğu zaman hata veriyor... } \\
\text {...raporların çıtısını alarak dosyalamasını yapmak daha } \\
\text { pratik... } \\
\text {...grafilere ve raporlara ulaşılamıyor... }\end{array}$ \\
\hline Erişim & $\begin{array}{l}\text {...üye olamıyoruz, onay için mesaj gelmiyor... } \\
\text {...uygulamaya giriş yapılamıyor, internetiniz yavaşladı uyarısı } \\
\text { veriyor... } \\
\text {...bir gün boyunca hiç giriş yapamadı̆̆ım oluyor... } \\
\text {...kaydolamıyorum, hasta bilgilerine yanlış diyor... }\end{array}$ \\
\hline Fayda Sağlama & $\begin{array}{l}\text {...uygulama içerik olarak da oldukça faydalı. İlk yardım çantas } 1 \\
\text { gibi, cebinizden ayırmayın... } \\
\text {...çok faydalı bir uygulama... }\end{array}$ \\
\hline Kullanılabilirlik & $\begin{array}{l}\text {...yeni ara yüz çok kullanışlı olmuş... } \\
\text {...uygulama basit, anlaşı1ı... } \\
\text {...büyük, küçük tansiyon hatta nabız eş zamanlı } \\
\text { kaydedilebilmeli... } \\
\text {...uygulama yavaş, insanı sinir ediyor İndirdiğime pişman } \\
\text { oldum indirmeyin... }\end{array}$ \\
\hline Güvenlik & $\begin{array}{l}\text {...T.C. kimlik numaram ile yapılacak her türlü şeyden Google } \\
\text { Play ve X hastanesi sorumludur... } \\
\text {...dikkat! İstediği izinler çok fazla, bilgilerimizi ne } \\
\text { yapacaksınız... }\end{array}$ \\
\hline
\end{tabular}


Temaların yoğunluk grafiğgi Şekil 1'de verilmektedir. Buna göre en çok yorumun randevu konusunda yapıldı̆̆g, en az yorumun ise güvenlik konusunda yapıldığı görülmektedir. Bu durum mobil sağlık uygulamalarının randevu alımında kullanıldığını ve kullanıcıların bu konuya önem verdiğini göstermektedir.

\section{1. Özel A Hastanesi Mobil Sağlık Uygulaması}

Mobil sağlık uygulaması Google Play Store' da 50.000 kişi tarafından indirilmiştir ve kullanıcılar tarafından 5 üzerinden 3.8 puan verilmiştir. Apple Store' da indirme sayısı belirtilmemiştir ve kullanıcılar tarafindan yine 5 üzerinden 2.2 puan verilmiştir. Bu uygulama içerisinde, sağlık kartı, randevular, tıbbi kayıtlar, sağlık uygulamaları sekmeleri yer almaktadır. Bunların yanı sıra hastane grubuna ait tüm hastanelere ulaşılabilen ve yol tarifi içeren hastaneler sekmesi, ambulans çağırmalarını kolaylaştıracak ambulans sekmesi, kullanıcılara ilk yardım ile ilgili konularda bilgi veren ilk yardım sekmesi mevcuttur. Randevular sekmesi randevu almaya ve daha önce alınan randevuları görmeye imkân sağlamaktadır. Randevu alınırken istenilen hastane, istenilen bölüm, istenilen doktor seçilmektedir ve bu durum uygulamayı kullananlara fayda sağlamaktadır. Sağlık kayıtları sekmesi kullanıcılara sürekli kullandıkları ilaçları, alerjileri, hastalıklarını, ameliyatlarını kaydedebilme şansı tanımaktadır. Bu sekme hastaların ilaçlarını, sürekli hastalıklarını takibi açısından kolaylık sağlayabilmektedir. Tıbbi kayıtlar sekmesi kullanıcılar için hastanede yapılan tüm laboratuvar ve muayene sonuçları ve raporlarına erişim imkânı sağlamaktadır.

\section{2. Özel B Hastanesi Mobil Sağlık Uygulaması}

Mobil sağlık uygulaması Google Play Store’ da 5.000 kişi tarafından indirilmiştir ve kullanıcılar tarafından 3.0 puan verilmiştir. Apple Store' da indirme sayısı belirtilmemiştir ve kullanıcılar tarafindan uygulamaya puan verilmemiştir. Bu uygulama içerisinde, hastaneler, randevular, sonuçlar, anlaşmalı kurumlar, canlı destek sekmeleri yer almaktadır.

\subsection{A Kamu Hastanesi Mobil Sağlık Uygulaması}

Mobil sağlık uygulaması Google Play Store’ da 5.000 kişi tarafından indirilmiştir ve kullanıcılar tarafından 4.1 puan verilmiştir. Apple Store' da indirme sayısı belirtilmemiştir ve kullanıcılar tarafından uygulamaya puan verilmemiştir. $\mathrm{Bu}$ uygulama içerisinde, randevular, laboratuvar sonuçları, rapor, radyoloji sekmeleri yer almaktadır. Kullanıcılara kolaylık sağlayacak ambulans sekmesi, konum sekmesi de yer almaktadır. Randevular sekmesi hastane randevu ve öğretim üyesi muayenesi olmak üzere iki kısımdan oluşmaktadır ve bu durum hastaların istediği doktordan randevu almasına imkân sağlamaktadır. Laboratuvar sonuçları, rapor, radyoloji sekmelerinde ise hastanede yapılan işlemlerin bilgileri ve sonuçları yer almaktadır.

\subsection{B Kamu Hastanesi Mobil Sağlık Uygulaması}

Mobil sağlık uygulaması Google Play Store’ da 10.000 kişi tarafından indirilmiştir ve kullanıcılar tarafından 4.1 puan verilmiştir. Apple Store' da indirme sayısı belirtilmemiştir ve kullanıcılar tarafından 3.4 puan verilmiştir. Bu uygulama içerisinde, randevular, laboratuvar sonuçları, rapor, radyoloji sekmeleri yer almaktadır. Bunların yanı sira konum, mail, 112 arama, hastane bilgi sekmeleri de mevcuttur. Randevular sekmesi hastane randevu ve öğretim üyesi muayenesi olmak üzere iki kısımdan oluşmaktadır ve bu durum hastaların istediği doktordan randevu almasına imkân sağlamaktadır. Konum sekmesi kullanıcıya yol tarifi sağlama, mail sekmesi kuruma doğrudan ulaşabilme imkânı sağlaması açısından kullanıcılara kolaylık sağlamaktadır.

\subsection{Kamu Hastanesi Mobil Sağlık Uygulaması}

Mobil sağlık uygulaması Google Play Store' da 10.000 kişi tarafından indirilmiştir ve kullanıcılar tarafından 4.0 puan verilmiştir. Apple Store' da indirme sayısı belirtilmemiştir ve kullanıcılar tarafindan uygulamaya 1.8 puan verilmiştir. Bu uygulama içerisinde, randevular, laboratuvar sonuçları, rapor, radyoloji sekmeleri yer almaktadır. Bunların yanı sıra alt sekmeler olarak; konum, arama, kullanıcı sekmeleri mevcuttur. Randevular sekmesi, randevu almaya ve randevu iptal etmeye imkân sağlamaktadır. Bu sayede kolay bir şekilde randevu alınabilmektedir. Laboratuvar sonuçları, rapor, radyoloji sekmeleri hastanede yapılan işlemlere ait tetkik sonuçlarını içermektedir. Diğer sekmeler ise bazı kısa yollar içererek kolaylıklar sağlamaktadır. 
Şekil 1. Temalara Ait Grafik

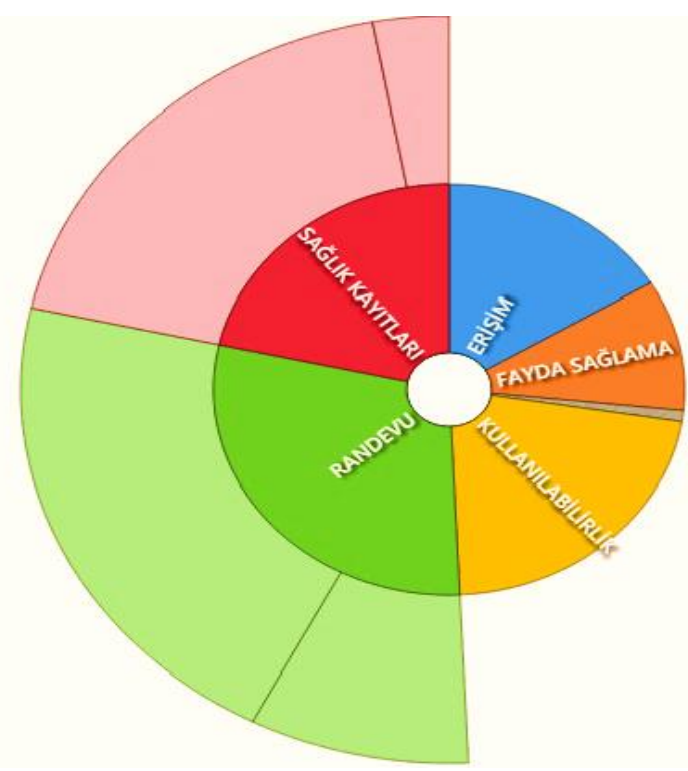

\section{BULGULAR}

İçerik analizleri çalışma kapsamında yer alan hastanelere ilişkin bulgular aşağıda yer almaktadır. Ayrıca, kategorilere ayrılmayan temalar vardır.

\section{1. Özel A Hastanesi’nde Oluşan Temalara İlişkin Bulgular}

Şekil 2'ye göre Özel A Hastanesi'nde randevu, sağlık kayıtları, erişim, fayda sağlama, kullanılabilirlik temalarının ortaya çıktığı görülmektedir. Randevu teması memnuniyet ve memnuniyetsizlik, sağlık kayıtları teması ise laboratuvar ve muayene kayıtları ve rapor olmak üzere iki kategori şeklinde incelenmiştir. Erişim, fayda sağlama ve kullanılabilirlik temaları kategorilere ayrılmamıştır.

Şekil 2. Özel A Hastanesi Temaları

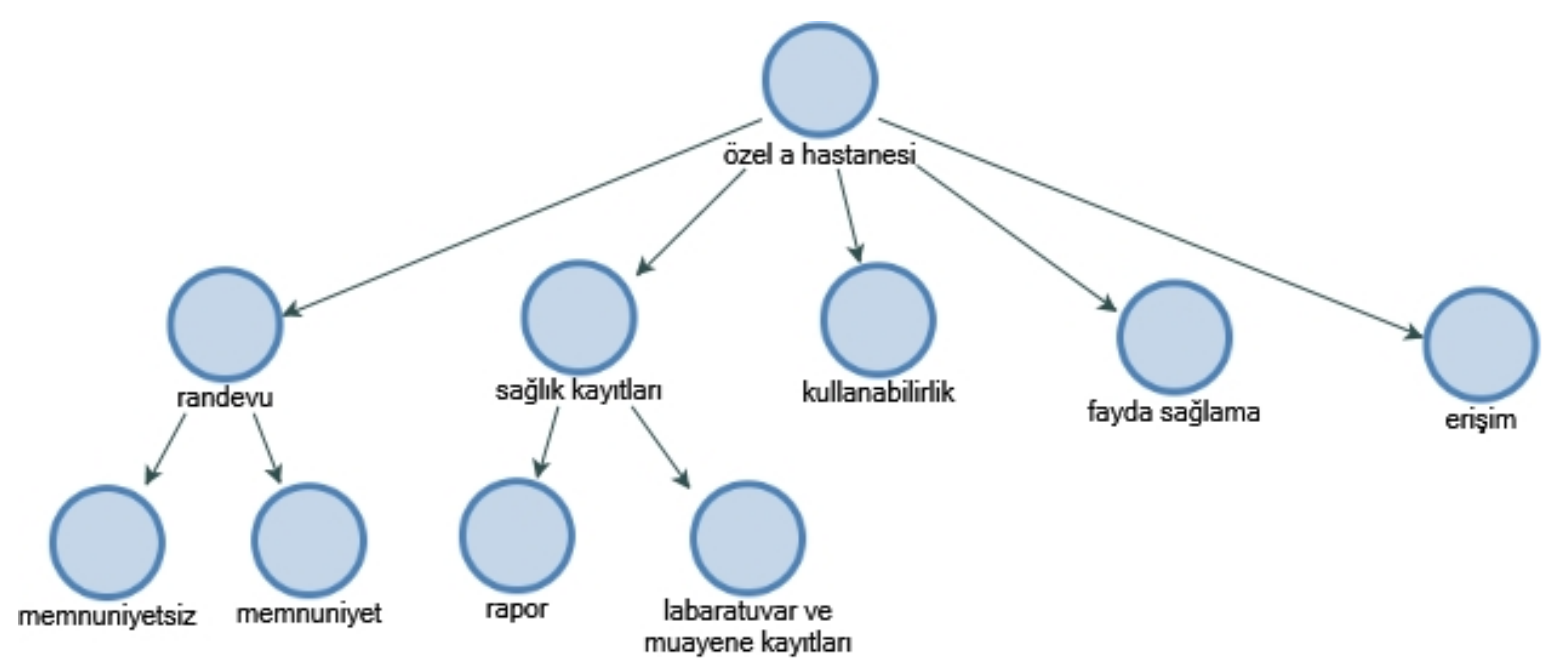




\section{2. Özel B Hastanesi'nde Oluşan Temalara İlişskin Bulgular}

Şekil 3'e göre Özel B Hastanesi'nde randevu, erişim, kullanılabilirlik temaları ortaya çıkmıştır. Randevu teması memnuniyet ve memnuniyetsizlik olmak üzere iki kategori şeklinde incelenmiştir. Erişim ve kullanılabilirlik temaları kategorilere ayrılmamıştır.

Şekil 3. Özel B Hastanesi Temaları

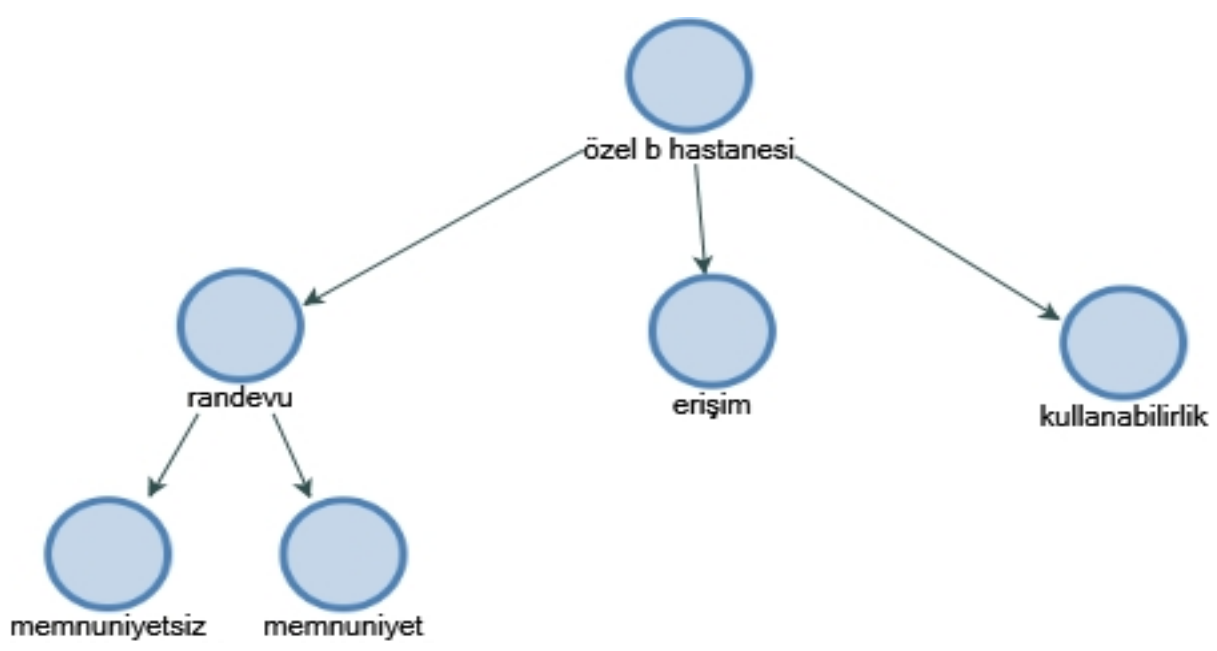

\subsection{A Kamu Hastanesi'nde Oluşan Temalara İlişskin Bulgular}

Şekil 4'e göre A Kamu Hastanesi'nde randevu, sağlık kayıtları, güvenlik erişim, fayda sağlama, kullanılabilirlik temaları ortaya çıtığı görülmektedir. Randevu teması memnuniyet ve memnuniyetsizlik, sağlık kayıtları teması ise laboratuvar ve muayene kayıtları ve rapor olmak üzere iki kategori şeklinde incelenmiştir. Erişim, fayda sağlama, kullanılabilirlik ve güvenlik temaları kategorilere ayrılmamıştır.

Şekil 4. A Kamu Hastanesi Temaları

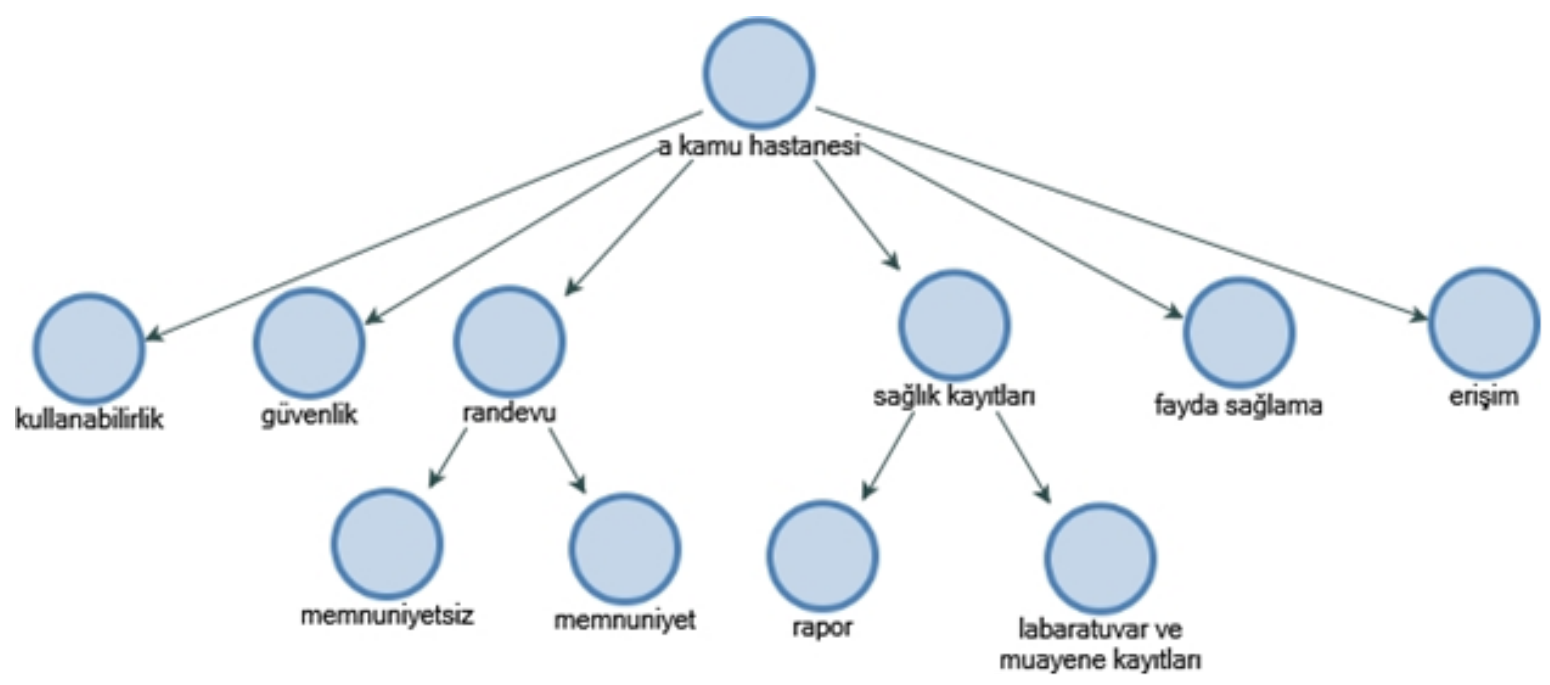

\subsection{B Kamu Hastanesi'nde Oluşan Temalara İlişkin Bulgular}

Şekil 5'e göre B Kamu Hastanesi'nde randevu, sağlık kayıtları, erişim, fayda sağlama ve kullanılabilirlik temaları ortaya çıkmıştır. Randevu teması memnuniyet ve memnuniyetsizlik, sağlık kayıtları teması ise laboratuvar ve muayene kayıtları ve rapor olmak üzere iki kategori şeklinde incelenmiş̧ir. Erişim, fayda sağlama ve kullanılabilirlik temaları kategorilere ayrılmamıştır. 
Şekil 5. B Kamu Hastanesi Temaları

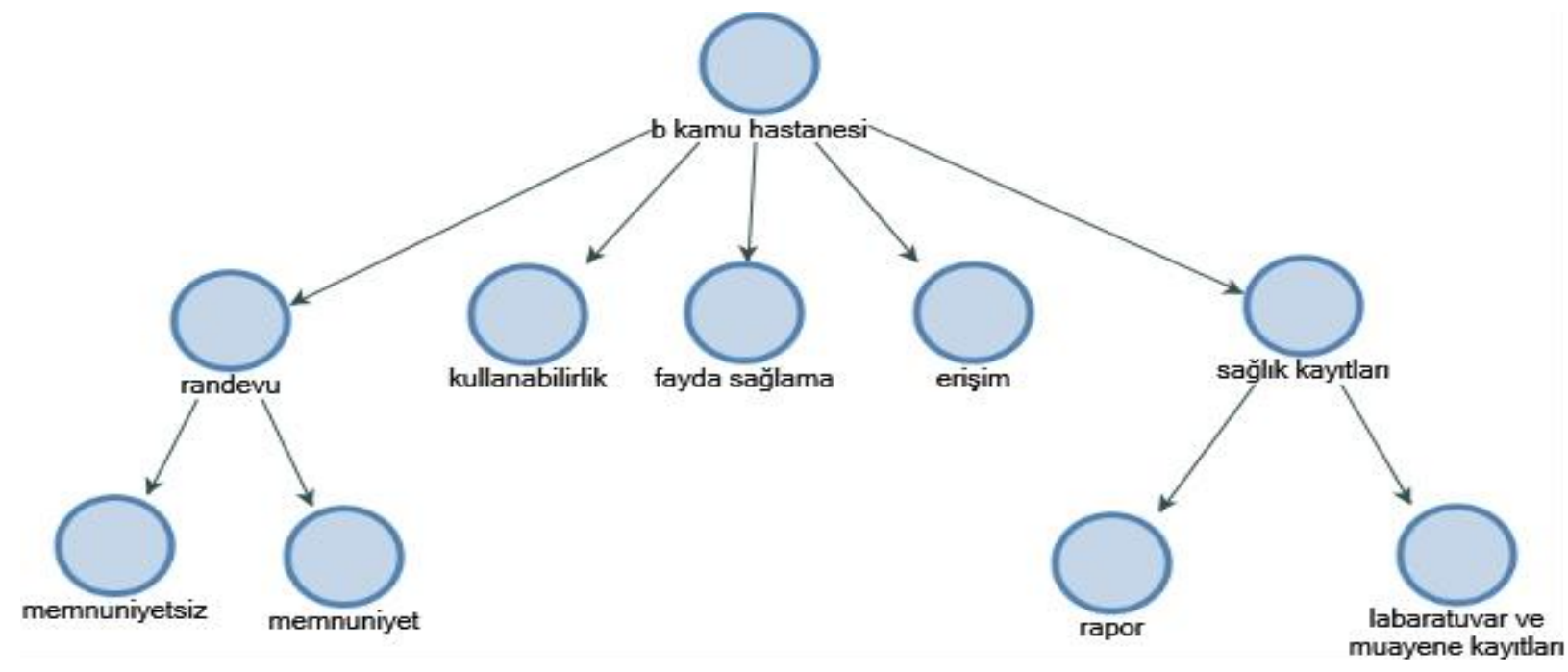

\subsection{Kamu Hastanesi'nde Oluşan Temalara İlişkin Bulgular}

Şekil 6'ya göre C Kamu Hastanesi'nde randevu, sağlık kayıtları, erişim, fayda sağlama, kullanılabilirlik, güvenlik temaları ortaya çıkmıştır. Randevu teması memnuniyet ve memnuniyetsizlik, sağlık kayıtları laboratuvar ve muayene sonuçları ve rapor olmak üzere iki kategori şeklinde incelenmiştir. Erişim, fayda sağlama, kullanılabilirlik ve güvenlik temaları kategorilere ayrılmamıştır.

Şekil 6. C Kamu Hastanesi Temaları

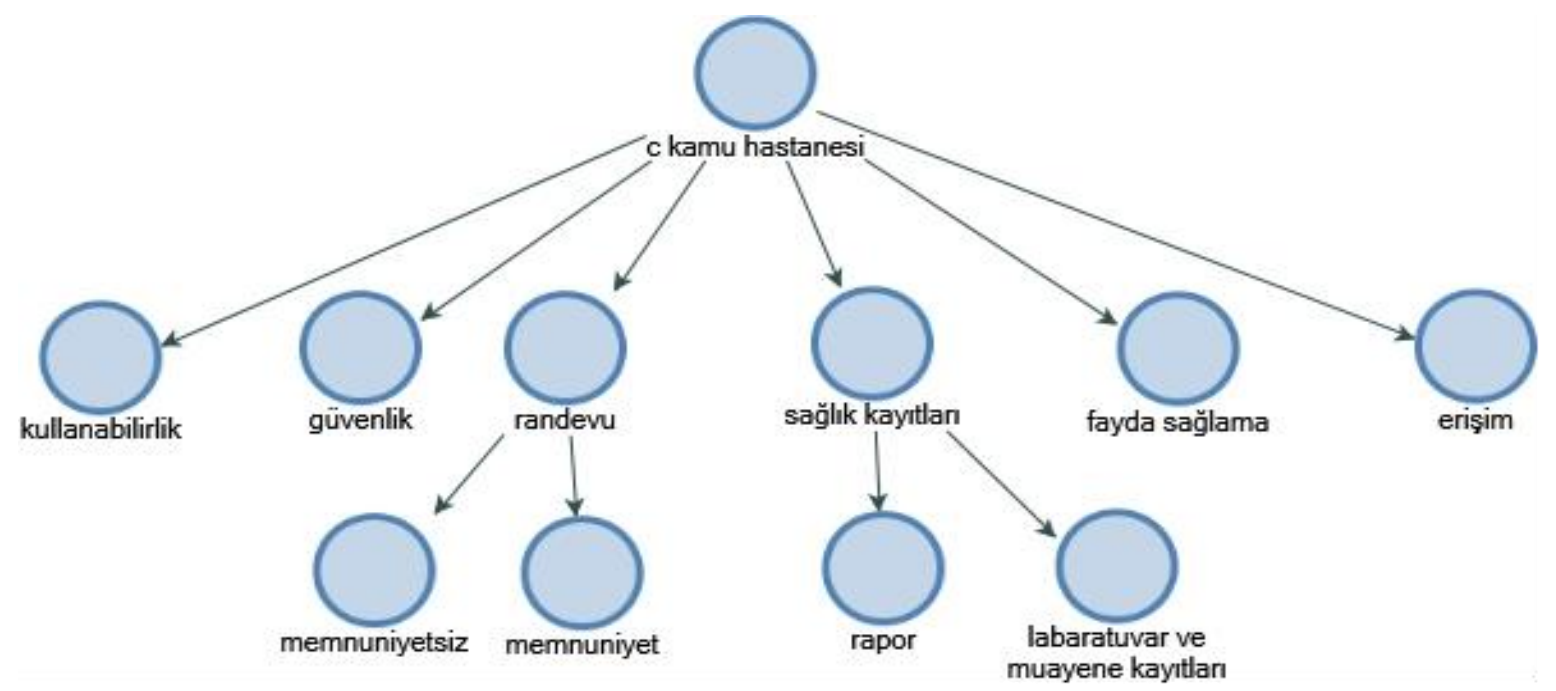

\section{SONUÇ VE ÖNERİLER}

Mobil uygulamalar çeşitli sektörlerde olduğu gibi sağlık sektöründe de önemli bir yer tutmaktadır. Zaman geçtikçe gerek kamu hastaneleri gerekse özel hastaneler mobil uygulamaları kullanmaya başlamıştır. Hastaneler tarafindan geliştirilen mobil sağlı uygulamaları tedavi süreci ve sonrası ile ilgili birçok işlemin uygulama üzerinden yapılmasına olanak sağladığı için hastalara çeşitli kolaylıklar sağlamaktadır. Bu sağlanan kolaylıklara örnek olarak bireylerin kilo yönetimine ilişkin mobil uygulamaların bireyleri sürekli olarak takip edilmesini sağlaması ve bireyin de her gün düzenli ve daha bilinçli olarak kendisini takip etmesi gösterilebilir (Burke vd., 2012: 20). Ayrıca, hasta takip ve izlemede göğüs ve ortopedi ameliyatları sonrası mobil uygulamaların kullanıldığı da bilinmektedir. $\mathrm{Bu}$ sayede cerrahlara esneklik sağlanmakta ve muhtemel komplikasyonlarda erken müdahale imkanını arttırmaktadır (Semple vd., 2015:8). 
Araştırma kapsamına incelenen hastanelerin mobil sağlık uygulamalarının içerikleri ve mobil sağlık uygulamalarına yapılan yorumlar incelenmiştir. Elde edilen veriler sonucunda randevu, sağlık kayıtları, erişim, kullanılabilirlik, fayda sağlama, güvenlik olmak üzere 6 tema ortaya çıkmıştır. Hastane uygulamalarına yapılan yorumlar, oluşturulan temalar çerçevesinde her hastane için ayrı olarak ele alınmıştır. Hastane mobil sağlık uygulamalarına yapılan yorumlara bakıldığında her temanın her hastane için ortaya çıkmadığı görülmüştür. Bu durum göstermektedir ki her mobil uygulamada aynı sekmeler yer almamaktadır ve hastaneler birbirinden farklı özelliklere sahip uygulamalar geliştirmişlerdir.

Yukarıda yer alan Şekil 1'de görüldüğü gibi üzerinde en çok veri elde edilen tema 'Randevu Teması' dır. Randevu teması 'memnuniyet' ve 'memnuniyetsizlik' olmak üzere iki kategori de toplanmıştır. Mobil sağlık uygulamalarına yapılan yorumlar incelendiğinde beş hastaneden de randevu ile ilgili veri elde edilmiştir. Bu da göstermektedir ki ele alınan hastane mobil uygulamalarının hepsi randevu alımı için kullanılmaktadır. Mobil uygulamaların randevu alımı için kullanılmasında memnun olanlar kadar memnun olmayanların da olduğu varılan sonuçlardan birisidir. Genel olarak bakıldığında mobil sağlık uygulamaların randevu alımında kullanıldı ̆̆ ve randevu alımını kolaylaştırdığı görülmüştür. Demir ve Arslan (2017: 79) tarafından yapılan çalışmada uygulamaların, hastanın sağlık kurumundan randevu alması, tedavi süreci ve tedavi süreci sonrasında kişinin hayati bulgularının izlenmesinde etkili olarak kullanılabileceği iddia edilmektedir. Bu sonuç çalışmamız ile benzerlik göstermektedir. Ancak randevu alınması esnasında randevu iptalinin uygulamadan yapılamaması, randevu sekmesine girişte yaşanan sorunlar, randevu alım sırasında doktor adının seçilememesi, randevu alınan bölümün seçilmemesi gibi bazı sorunlar yaşandığı sonuçlarına da ulaşılmıştır.

Üzerinde en çok veri elde edilen ikinci tema 'Sağlık Kayıtları Teması' olmuştur. Sağlık kayıtları teması 'Laboratuvar ve Muayene Sonuçları' ve 'Raporlar' olmak üzere iki kategoride toplanmıştır. Özel B Hastanesinin temalarına ait modele baktığımızda sağlık kayıtları temasının olmadığı görülmektedir. Bu da göstermektedir ki Özel B Hastanesinin mobil sağlık uygulamasında sağlık kayıtlarının yer aldığı bir sekme yoktur. Sağlık kayıtları temasının yer aldığı hastanelerin yorumlarına bakıldığında mobil sağlık uygulamalarında laboratuvar ve muayene sonuçlarının yer almasının kullanıcıların işini kolaylaştırdığı sonucuna ulaşılmıştır. Bu sonuca benzer bir sonuç, Demir ve Arslan (2017: 78), tarafından yapılan bir çalışmada da elde edilmiştir. Çalışma sonucuna göre sağlık hizmetlerinde yer alan verilerin çok olmasından dolayı bu verilerin bulut sistemlerinde erişime açık bir şekilde bulundurulması, sağlık hizmetlerinin daha etkili sunulabilmesi için önem taşımaktadır. Bu yüzden hastaya ilişkin bilgilerin hastane düzeyinde ilgili kişilerin erişimine açık olması gerekmektedir. Çünkü bu şekilde hastalar istedikleri yerde ve zamanda bu bilgilere kolayca ulaşabileceklerdir. Ayrıca sonuçlarını almak ve hastanede beklemek zorunda olmadıkları için zamandan tasarruf sağlayabildikleri de ulaşılan diğer sonuçlardandır.

Erişim temasına ait yorumlara bakıldığında ele alınan beş hastaneden de veri elde edilmiştir. Erişimle ilgili genelde olumsuz yorumlar olduğu görülmektedir. Uygulamaya girişte ve üye olunmasında bir takım problemler yaşanmaktadır. Üye olma işlemi esnasında telefona gelen onay mesajının geç geldiği ya da hiç gelmediği için mobil uygulamalara üye olunurken sorunlar yaşandığına ulaşılmıştır. Bu durum uygulamalara erişimi engellemektedir. Kullanıcılar sorunların çözülmesini istemektedir. Erişim sağlanamayan uygulamalardan fayda elde edilemeyeceği için bu durumlara dikkat edilmesi önerilmektedir. Çünkü mobil sağlı uygulamalarının geliştirilme amaçlarından biri kullanıcılarına fayda sağlamasıdır.

Kullanılabilirlik temasına ait yorumlara bakıldığında ele alınan beş hastaneden de veri elde edilmiştir. Yorumların genellikle uygulamaların ara yüzlerine ve kullanımlarının basit, kolay, pratik olması ile ilgili olduğu görülmüştür. Uygulamaların kullanımlarının basit olması ve ihtiyaçlarını karşılayacak nitelikte olması kullanıcılar için büyük önem taşımaktadır.

Güvenlik temasına ait yorumlara bakıldığında A Kamu Hastanesi ve C Kamu Hastanesi mobil uygulamalarına giriş esnasında istenen izinlerin, kullanıcıların güvenli olmadığı düşüncesine kapılmalarına yol açtığı görülmüştür. Diğer hastanelerde güvenlik ile ilgili yorumlara yer verilmemiştir. Güncel çalışmalara göre bulut bilişim sistemlerinde hasta bilgilerinin depolanması ve yönetilmesinin gizlilik ve güvenlik açısından bir takım riskler taşımaktadır (Rasche vd., 2018: 8; Demir ve Arslan, 2017: 77). Mobil sağlık uygulamalarının kullanılmama sebepleri arasında bilgilerin doğruluğuna güvenilmemesi ve veri gizliliğinin korunmadığı düşüncesi yer almaktadır. Bu durum çalışmamızda ortaya çıkan mobil uygulamalara olan güvensizlik ile benzerlik göstermektedir. Güvensizlik hissiyatına sahip bir takım kullanıcılar olsa dahi kullanıcıların hastaneler tarafından geliştirilen mobil sağlık uygulamalarının genel olarak kendilerine fayda sağladığını düşündükleri sonucuna varılabilir. $\mathrm{Bu}$ sonuç Arslan ve Demir (2017: 79), tarafından yapılan çalışma sonuçlarına göre benzerlik göstermektedir ve mobil sağlık kullanıcıları kişisel sağlık kayıtlarını faydalı bulmakta ve bu konuda genel olarak 
olumlu düşünmektedirler. Ayrıca uygulamaların randevu alımını, sağlık kayıtlarına erişimini ve ilaç takiplerinin yapılmasını sağlaması gibi nedenlerden dolayı özellikle kronik hastalığa sahip bireylerin tedavi süreçlerine ve sürecin daha hızlı ilerlemesine de katkı sağladığı sonuçlarına da varılabilir. Doğanyiğit (2014: 52), tarafından yapılan çalışma sonucuna göre, ciddi sağlık problemleri ve kronik hastalıkları olan bireyler, son zamanlarda sağlığı konusunda belirli bir değişim yaşayanlar, mobil uygulamaları kullanmaya daha eğilimlilerdir. Bu uygulamaların \%19’u özellikle sağlıklarını izlemek ve yönetmek için kullanılmaktadır. Bunlara ek olarak yapılan çalışmada uygulamaların kullanımı sırasında karşılaşılan sorunlar da ortaya konulmaya çalışılmıştır. Uygulamaların kullanımı sırasında ortaya çıkan bu sorunlar üzerinde iyileştirmeler yapılırsa kullanıcılara sağlayacağı fayda düzeyinin ve uygulamaların kullanımlarının artacağı düşünülmektedir. Bu sebeple kullanıcıların fikirlerinin dikkate alınarak uygulamalar üzerinde güncellemeler ve iyileştirmeler yapılması önerilmektedir. Çünkü mobil sağlık uygulamalarının hastaları daha bilinçli hale getireceği, sağlık kuruluşları ve hekimler üzerindeki yükü hafifleteceği ve hekim-hasta-hastane iletişimini devamlı kılacağı düşünülmektedir.

\section{KAYNAKÇA}

Adibi, S. (2015). “Mobile Health A Technology Road Map”, Springer International Publishing.

Ağaç, F. (2015). "Mobil Uygulamalar Sağlık Sistemini Kişiselleştiriyor”, http://www.bilisimdergisi.org/s174, (Erişim Tarihi: 19 Nisan 2019).

Arslan, E.T. ve Demir, H. (2017). “Üniversite Öğrencilerinin Mobil Sağlık ve Kişisel Sağlık Kaydı Yönetimine İlişkin Görüşleri”, Aksaray Üniversitesi İktisadi ve İdari Bilimler Fakültesi Dergisi, 9(2), 17-36.

Burke, L.E., Styn, M.A., Sereika, S.M., Conroy, M.B., Ye, L., Glanz, K., Sevick M.A. ve Ewing, L.J. (2012). "Using Mhealth Technology to Enhance Self-Monitoring For Weight Loss: A Randomized Trial", American Journal of Preventive Medicine, 43(1), 20-26.

Demir, H. ve Arslan, E.T. (2017). "Mobil Sağlık Uygulamalarının Hastanelerde Kullanılabilirliği: Hastane Yöneticileri Üzerine Bir Araştırma”, KMÜ Sosyal ve Ekonomik Araştırmalar Dergisi, 19(33), 71-83.

Eng, T.R. (2004). "Population Health Technologies Emerging Innovations for the Health of the Public", American Journal of Preventive Medicine, 26(3), 237-242.

Free, C.F., Phillips, G., Galli, L., Watson, L., Felix, L., Edwards, P., Patel, V. ve Haines. A. (2013).’The Effectiveness of Mobile-Health Technologies to Improve Healthcare Service Delivery Processes: A Systematic Reviewand Meta-Analysis", Plos Medicine, 10, 1-26.

Göktaş, B., Önder, Ö.R., Duran, M., Şakar, S., Yılmaz, M., Güler, S., Çınar, İ., Çamlıdağ, T., Şenkal, Y. ve Özdemir, G. (2017). “Türkiye'de Sağlık Bilgi Sistemleri Üzerine Bir Araştırma”, Ankara Sağlık Bilimleri Dergisi, 1-2-3, 125-138.

Güler, E. ve Eby, G. (2015). “Akıllı Ekranlarda Mobil Sağlık Uygulamaları”, Eğitim ve Öğretim Araştırma Dergisi, 4(3), 45-51.

Haux, R. (2006). "Health Information Systems; Past, Present, Future", International Journal of Medical Informatics. 75, 268-281.

Holzinger, A., Dorner, S., Födinger, M., Calero Valdez, A. ve Ziefle, M. (2010). "Chances of Increasing Youth Health Awareness through Mobile Wellness Applications", Proceedings of the 4th Symposium of the Workgroup Human- Computer Interaction, 71-81.

Kırlar Can, B., Yeşilyurt, H., Sancaktar, L.C. ve Koçak, N. (2017). "Mobil Çağda Mobil Uygulamalar: Türkiye'deki Yerli Otel Zincirleri Üzerine Bir Durum Tespiti”, Journal of Yasar University, 12(45), 6075.

Kopmaz, B. ve Arslanoğlu, A. (2018). "Mobil Sağlık ve Akıllı Sağlık Uygulamaları”, Sağlık Akademisyenleri Dergisi, 5(4), 251-255.

Kuersten, R. (2010). 500 Million People Will be Using Mobile Health Applications in 2015, http://www.prnewswire.com/newsreleases/500-million-people-will-be-using-mobile-healthapplicationsin-2015-107160173.html, (Erișim Tarihi: 19 Nisan 2019). 
Kumar, S., Nilsen, W.J., Abernethy, A., Atienza, A., Patrick, K. ve Pavel, M. (2013). "Mobile Health Technology Evaluation: The mHealth Evidence Workshop", Am J Prev Med, 45(2), 228-236.

Liu, C., Zhu, Q., Holroyd, K.A. ve Seng, E.K. (2011). "Status and Trends of Mobile-Health Applications For İos Devices: A Developer's Perspective", Journal of Systems and Software, 84(11), 2022-2033.

Luxton, D.D., Hansen, R.N. ve Stanfill, K. (2014). "Mobile App Self-Care Versus In-Office Car Efor Stress Reduction: A Cost Minimization Analysis”, Journal of Telemedicine and Telecare, 20(8), 431-435.

Mandl, K.D., Mandel, J.C. ve Kohane, I.S. (2015). "Driving Innovation in Health Systems through an Apps-Based Information Economy”, Cell Systems. 1(1), 8-13.

Mechael, P.N. (2009). “The Case for Mhealth in Developing Countries”, The Mit Press Journals, 4(1), 103-118.

Owensbya J.K. ve Kavookjianb, J. (2017). "Pharmacy Students' Perceptions of the Usefulness of Motivational Interviewing and The Use of Mobile Health Applications on Patient Counseling in The Future", Currents in Pharmacy Teaching and Learning, 9(4), 511-738.

Öney Doğanyiğit, S. (2013). En fazla kullanılan mobil sağlık aplikasyonları neler?, http://fesraoz.blogspot.com/2013/09/en-fazla-kullanilan-mobil-saglik.html, (Erişim Tarihi: 19 Nisan 2018).

Öney Doğanyiğit, S. (2014). Sağlık Hizmetleri İletişiminde Mobil Sağlık: ‘Adımsayar’ Uygulaması Örneği. Yüksek Lisans Tezi, Galatasaray Üniversitesi Sosyal Bilimler Enstitüsü, İstanbul.

Patil, D.A. (2011). "Mobile For Health (mHealth) In Developing Countries: Application of 4 Ps of Social Marketing, Journal of Health Informatics In Developing Countries, 5(2), 317- 326.

Rashe, P. (2018). Prevalence of Health App Use Among Older Adults in Germany: National Survey. Jmır Mhealth and Uhealth.

Safran, C. ve H. Goldberg. (2000). Electronic Patient Records and Impact of the Internet. International Journal of Medical Informatics. 60, 77-83.

Semple, J. L., Sharpe, S., Murnaghan, M. L., Theodoropoulos, J. ve Metcalfe, K.A. (2015). “Using A Mobile App For Monitoring Post-Operative Quality of Recovery of Patients At Home: A Feasibility Study", Jmır Mhealth and Uhealth, 3(1), 1-11.

Singh, A., Wilkinson, S. ve Braganza, S. (2014). "Smartphones and Pediatricappsto Mobilize Themedicalhome", The Journal of Pediatrics, 165, 606-610.

Tezcan, C. (2016). Sağlığa Yenilikçi Bir Bakış Açısı: Mobil Sağlık. Yayın No: Tüsiad-T/2016-03/575.

Uğur, N.G. ve Turan, A.H. (2015). “Üniversite Öğrencilerinin Mobil Uygulamaları Kabulü ve Kullanımı: Sakarya Üniversitesi Örneği”, İnternet Uygulamaları ve Yönetimi Dergisi, 6(2), 63-79.

Yıldırım, A. ve Şimşek, H. (2011). Sosyal Bilimlerde Nitel Araştırma Yöntemleri, Ankara: Seçkin Yayıncılık.

World Health Organization (WHO). (2010). Telemedicine: Opportunities and Developments in Member States: Global Observatory for eHealth Series-Volume 2. Switzerland: WHO Press. 